\title{
Bilateral Laryngocele Causing Epiglottic Deformity and Upper Airway Obstruction
}

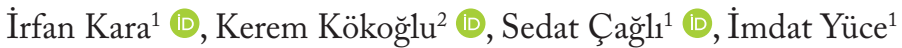 \\ Case Report $>{ }^{1}$ Department of Otorhinolaryngology, Erciyes University School of Medicine, Kayseri, Turkey \\ ${ }^{2}$ Department of Otorhinolaryngology, Develi HMK State Hospital, Kayseri, Turkey
}

Abstract

ORCID IDs of the authors: I.K. 0000-0003-3884-3014; K.K. 0000-0003-1749-7095; S.Ç. 0000-0003-4913-8687; i.Y. 0000-0003-0938-4437.

Cite this article as: Kara I, Kökoğlu K, Çağlı S, Yücel. Bilateral Laryngocele Causing Epiglottic Deformity and Upper Airway Obstruction. Turk Arch Otorhinolaryngol 2019; 57(2): 99-101.

\section{Corresponding Author:} Kerem Kökoğlu; dr.kokoglu@gmail.com

Received Date: 19.11.2018

Accepted Date: 28.01.2019

Available Online Date: 14.03.2019

DOI: 10.5152/ta0.2019.3949

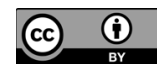

Content of this journal is licensed under a Creative Commons Attribution 4.0 International License.

Available online at www.turkarchotolaryngol.net
Laryngocele is the cystic dilatation of laryngeal ventricle. Most cases are asymptomatic and incidentally diagnosed in radiologic examinations. Although the etiology is unclear, obstruction, laryngeal pressure, congenital defects are possible risk factors. Computed tomography is the best method for diagnosis. Endoscopic, external or combined approaches have been described in the surgical treatment. Laryngocele should be kept in mind in patients with acute upper airway obstruction. Such patients may require tracheostomy. Some patients with laryngocele can also have laryngeal cancer, in which case direct laryngoscopy must be performed. This report presents a case with respiratory distress associated with bilateral laryngocele, and his management in the light of the literature.

Keywords: Laryngeal diseases, laryngocele, acute respiratory distress, computed tomography

\section{Introduction}

Laryngocele is a cystic dilation of the laryngeal saccule, which is in communication with the laryngeal lumen. It is usually asymptomatic and incidentally revealed in radiological examinations. Some patients may present with acute respiratory distress and tracheotomy may be required. Although the etiology is unclear, obstruction, increased laryngeal pressure and congenital defects are the possible risk factors for laryngocele. It has no predilection for a certain side. Only $1 \%$ of the cases are bilateral. Radiological examinations are useful in making a diagnosis, determining its size, searching for associated malignancies and planning the treatment. Laryngocele may develop in association with laryngeal cancer, especially supraglottic cancer (1). Direct laryngoscopy must be done in every laryngocele case.

Laryngoceles are categorized as internal or combined. The formerly used classification of internal, external and combined laryngoceles is being abandoned since purely external laryngoceles cannot exist as laryngoceles originate at the laryngeal saccule. An internal laryngocele is confined within the false vocal fold, medial to the thyrohyoid membrane. A combined laryngocele extends upward and protrudes through the thyrohyoid membrane to the neck (2).

In this paper, a 70-year-old patient with bilateral laryngocele is presented and laryngocele is discussed with regard of the literature.

\section{Case Presentation}

A 70-year-old male patient presented with hoarseness, difficulty in inspiration and swallowing. He had a 55-year history of smoking and a left neck mass for seven years. He had no history with wind instruments or glassblowing. He had no complaints of the mass until another mass appeared on his right neck one week ago. His complaints had worsened. Inspiratory stridor and hoarseness were identified in his physical examination. There also were bilateral soft, semi-mobile neck masses in front of the sternocleidomastoid muscles. Endoscopic examination showed a bilateral mucosal mass that pushed the epiglottis through the mid- 
line and closed the airway (Figure 1). The patient was admitted and given $1 \mathrm{mg} / \mathrm{kg}$ methylprednisolone intravenously. Plain radiography of the antero-posterior neck and computed tomography (CT) of the neck showed bilateral well-circumscribed, airfilled masses revealing laryngocele (Figure 2). The patient was operated under general anesthesia for respiratory distress and bilateral laryngocele. No pathological conditions were identified in direct laryngoscopy. Laryngoceles were removed with an ex-

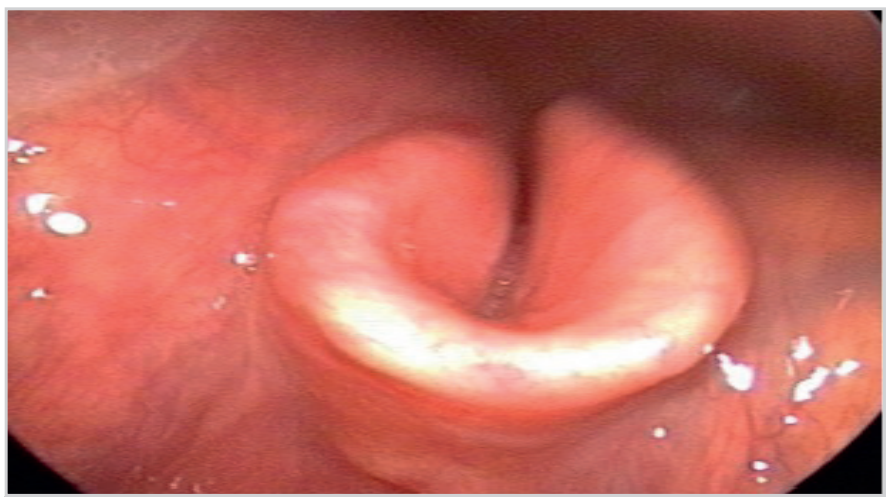

Figure 1. Bilateral laryngocele causing epiglottic deformity and narrowing airway
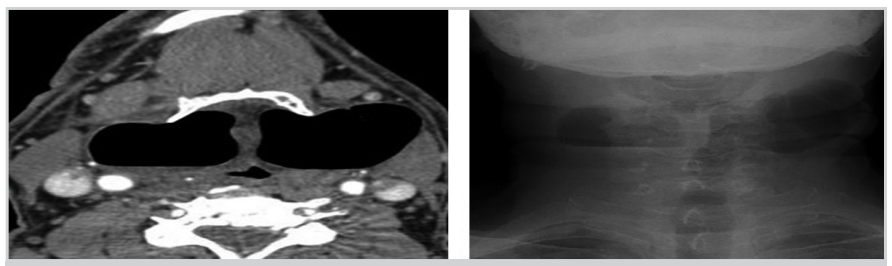

Figure 2. Computed tomography and plain radiography show bilateral air-filled, cystic structures

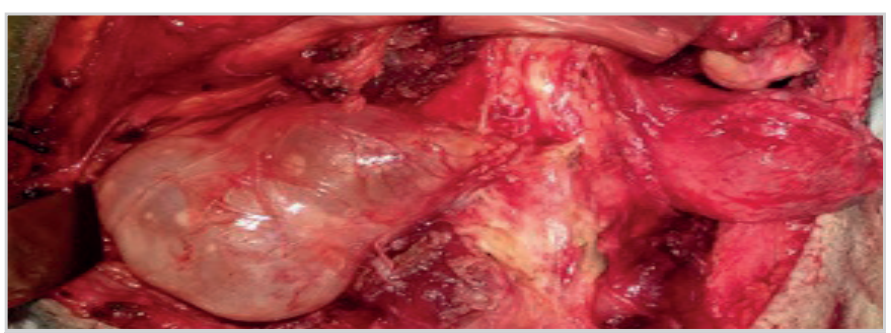

Figure 3. Intraoperative view of bilateral laryngocele

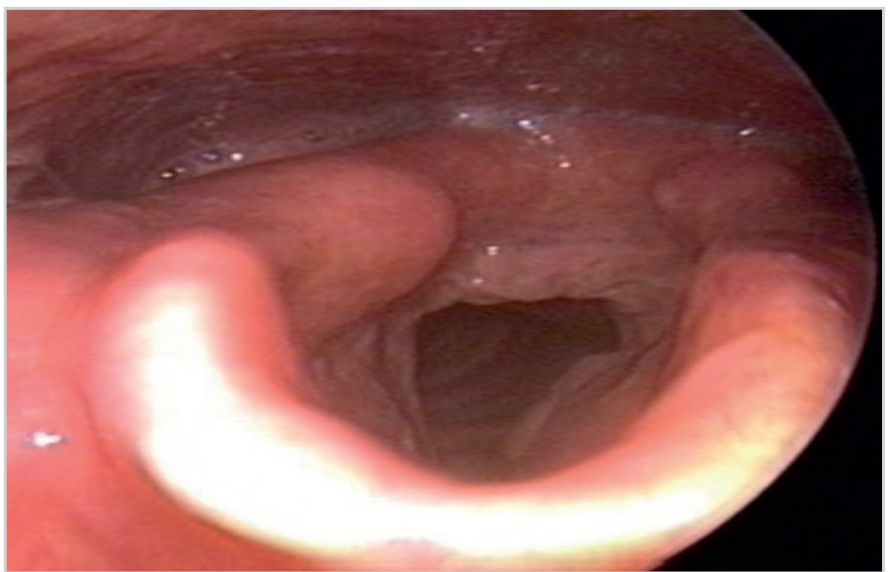

Figure 4. Postoperative view of the larynx ternal thyrohyoid membrane approach (Figure 3). His dyspnea and hoarseness healed postoperatively. The larynx was found normal in postoperative endoscopic examination (Figure 4). The histopathological examination confirmed laryngocele. Informed consent was obtained from the patient for the publication of this report and the images.

\section{Discussion}

Laryngocele is a rare disease. Although it can be seen at any age, it mostly occurs in the $5^{\text {th }} 7^{\text {th }}$ decades. It is five times more common in men than women. CT is very useful in diagnosis. Definitive diagnosis is done by surgical exploration, resection and pathological examination (2).

While its etiology is still unknown, congenital defects are suggested as a reason in newborn cases. Despite the anatomical variations and congenital defects seen in adults, it is difficult to explain all cases based on these reasons. Continuously increasing pressure in the laryngeal lumen can cause laryngocele in a normal larynx. Chronic cough, glassblowing and playing wind instruments are thought to be involved in the etiology of laryngocele (3). The presented case showed none of these etiologic factors.

Most cases are asymptomatic and incidentally diagnosed. If the case is symptomatic, it can cause hoarseness, difficulty in inspiration and swallowing, sore throat and cough (4). While some patients present with a neck mass that develops suddenly, others can present with acute respiratory distress and require an emergency tracheotomy (5). The presented case had a neck mass for seven years on the left side and another mass had developed suddenly on the right side. His respiratory distress decreased with steroids, so tracheotomy was not required.

Laryngocele has a narrow stalk which maintains its communication with the laryngeal lumen. When obstructed by a cyst filled with mucus, it is called laryngomucocele. Laryngomucopyocele is an infectious condition and patients exhibit symptoms such as deep neck infection (6). A laryngocele grows posterosuperiorly on the medial side and pushes the band ventricles and the aryepiglottic folds. A laryngocele can pass through the thyrohyoid membrane and enter the soft tissues of the neck. It usually passes through the opening of the superior laryngeal nerve. If a laryngocele in the neck is filled with liquid, it can be regarded as a branchial cyst (2).

The most useful imaging method is CT. A laryngocele is seen as a cyst filled with air or liquid in its normal location in the $\mathrm{CT}$, and appears as a well-circumscribed air-filled enlargement that represents extension and elongation of the laryngeal appendices (saccules) of the laryngeal ventricle (2). Lymphangioma, hemangioma, cystic hygroma, submandibular gland ductal cyst, pharyngeal diverticulum, teratoma, dermoid cyst, lymphoma, parotid tumor, ectopic thyroid tissue, branchial cyst, neurofibroma and lymphadenopathy must be considered in the differential diagnosis (2). Differential diagnosis can be done by CT, where a saccular cyst, thyroglossal cyst, branchial cyst, cystic hygroma 
or cancer can be identified (5). CT examination of our patient revealed bilateral, well-circumscribed air-filled cystic structures with regular borders. These cysts had caused epiglottic deformity.

Laryngocele is a rare condition, there is no consensus about its surgical treatment, and a number of surgical techniques are available. The traditional treatment is an external approach. Microlaryngoscopic surgery and $\mathrm{CO}_{2}$ laser treatment have become popular, especially in the last two decades, and especially in internal laryngocele cases (6). Symptomatic laryngocele can be treated with an external, an internal, or a combined approach (3). Asymptomatic cases can be monitored or excised (5). The surgical approach is related to the type and size of the laryngocele. Most patients with combined laryngoceles are treated with an external approach. The reported advantages of external approaches are good exposure of the laryngocele, a more precise procedure, and a low recurrence rate. Disadvantages are skin scarring, higher morbidity, longer duration of surgery, longer hospitalization period, and higher costs (2).

Combined laryngoceles can be treated with the endolaryngeal approach. Majority of internal laryngoceles are treated with an endolaryngeal (microlaryngoscopy) approach. Resection using a $\mathrm{CO}_{2}$ laser is currently the preferred and most frequently used type of surgery for internal laryngoceles. This technique is considered by many authors to be a quick, precise and safe alternative to an external approach with excision, allowing for fewer complications than its external counterparts, resulting in faster recovery of the patients as well as their voice (6).

The paraglottic space is seen better with a lateral thyrotomy technique. Less recurrence and morbidity are also seen with this technique (2). It is, however, invasive and can be complex for some cases. Endoscopic excision with a $\mathrm{CO}_{2}$ laser is an option for small, internal laryngoceles. Marsupialization or partial resection has a high rate of recurrence. Cold knife and microdebrider can also be used in an endoscopic approach (7).

Postoperative complications can be associated with an external approach. Wound infection, seroma, fistula, scar, hematoma are the general complications in a neck surgery. External approach can lead to injury of superior laryngeal artery and nerve (8).

The clinical approach in bilateral laryngocele is the same as long as there is no respiratory distress. Urgent surgery should be considered in cases with respiratory distress. Akbas et al. (9) reported a case of a bilateral laryngocele together with laryngeal cancer. As in every laryngocele case, the possibility of concomitant laryngeal cancer and bilateral laryngocele should be kept in mind. Bilateral laryngocele more often presents with respiratory distress and dyspnea. Aksoy et al. (10) reported a bilateral laryngocele case that was misdiagnosed as asthma and treated for four years. That respiratory pathologies could be associated with laryngeal conditions should always be kept in the mind.

\section{Conclusion}

Laryngocele is a rare cause of acute respiratory distress. Its etiology is still unknown. Most cases are asymptomatic. Different kinds of surgical techniques can be used depending on the type and the size of the laryngocele.

Informed Consent: Written informed consent was obtained from the patient who participated in this study.

Peer-review: Externally peer-reviewed.

Author Contributions: : Concept - İ.K., K.K.; Design - İ.K., S.Ç.; Supervision - S.Ç., İ.Y.; Resource - İ.K., S.Ç.; Materials - K.K. İ.Y.; Data Collection and/or Processing - İ.K., K.K.; Analysis and/or Interpretation - K.K., S.Ç.; Literature Search - İ.K., K.K.; Writing - İ.K., K.K.; Critical Reviews - S.Ç., İ.Y.

Conflict of Interest: The authors have no conflicts of interest to declare.

Financial Disclosure: The authors declared that this study has received no financial support.

\section{References}

1. Prasad N, Singh M, Nagori R, Singh S. Laryngopyocele: Presenting with pressure symptom. Int J Appl Basic Med Res 2015; 5: 228-30. [CrossRef]

2. Thomé R, Thomé DC, De La Cortina RA. Lateral thyrotomy approach on the paraglottic space for laryngocele resection. Laryngoscope 2000; 110: 447-50. [CrossRef]

3. Dursun G, Ozgursoy OB, Beton S, Batikhan H. Current diagnosis and treatment of laryngocele in adults. Otolaryngol Head Neck Surg 2007; 136: 211-5. [CrossRef]

4. Lancella A, Abbate G, Dosdegani R. Mixed laryngocele: a case report and review of the literature. Acta Otorhinolaryngol Ital 2007; 27: 255-7.

5. Bakır S, Gül A, Kınış V, Özbay M, Özkan H. A case of mixed type laryngocele presented with deep neck infection and review of the literature. J Clinical Experiment Invest 2012; 3: 415-9. [CrossRef]

6. Zelenik K, Stanikova L, Smatanova K, Cerny M, Komínek P. Treatment of laryngoceles: What is the progress over the last two decades? Biomed Res Biomed Res Int 2014; 2014: 819453.

7. Fraser L, Pittore B, Frampton S, Brennan P, Puxeddu R. Laryngeal debridement: an alternative treatment for a laryngopyocele presenting with severe airway obstruction. Acta Otorhinolaryngol Ital 2011; 31: 113-7.

8. Roediger FC, Eisele DW. Complications of Neck Surgery. In: Flint PW, editor. Cummings Otolaryngology, Head and Neck Surgery. Volume $2.5^{\text {th }}$ ed. Philadelphia: Elsevier; 2010. [CrossRef]

9. Akbas Y, Ünal M, Pata YS. Asymptomatic bilateral mixed-type laryngocele and laryngeal carcinoma. Eur Arch Otorhinolaryngol 2004; 261: 307-9. [CrossRef]

10. Aksoy EA, Elsürer Ç, Serin GM, Ünal ÖF. Bilateral internal laryngoceles mimicking asthma. J Res Med Sci 2013; 18: 453-6. 